\title{
Modified Lund Mackay Postoperative Endoscopy Score for defining inflammatory burden in chronic rhinosinusitis*
}

\author{
Kornkiat Snidvongs ${ }^{1,2}$, Dustin Dalgorf ${ }^{3}$, Larry Kalish ${ }^{4,5}$, Raymond Sacks ${ }^{1,4,5}$, \\ Eleanor Pratt ${ }^{6}$, Richard J. Harvey ${ }^{1,3,7}$ \\ 'Australian School of Advanced Medicine, Macquarie University, Australia \\ 2 Faculty of Medicine, Chulalongkorn University, Thailand \\ ${ }^{3}$ Department of Otolaryngology-Head and Neck, Skull Base Surgery, St Vincent's Hospital, Australia \\ ${ }^{4}$ Department of Otolaryngology, Concord General Hospital, Australia \\ ${ }^{5}$ Sydney Medical School, University of Sydney, Australia \\ ${ }^{6}$ Sydney School of Public Health, University of Sydney, Australia \\ ${ }^{7}$ St Vincent's Centre for Applied Medical Research, University of New South Wales, Australia
}

Rhinology 52: 53-59, 2013

DOl:10.4193/Rhino13.056

*Received for publication:

May 6, 2013

Accepted: August 14, 2013

\begin{abstract}
Objective: The Lund Mackay Postoperative Endoscopy Score (LMES) for chronic rhinosinusitis (CRS) is a poor measure of the patient experience. A proposed Modified Lund Mackay Postoperative Endoscopy Score (MLMES) aims to better describe the inflammatory burden in CRS.
\end{abstract}

Methods: A prospective study on CRS patients having endoscopic sinus surgery (ESS) was conducted. Endoscopy was recorded at the 6 th and the 12th week post-op. The MLMES recorded changes in mucosa, mucus and purulence for each of the maxillary, ethmoid, sphenoid, frontal sinuses and olfactory fossa in post-ESS cavities. The correlation between MLMES and visual analogue scale of total rhinosinusitis symptoms, global anchor score of nasal function, Sino-Nasal Outcome Test 22 (SNOT-22) and nasal symptom score was analyzed. The inter-observer reliability, intra-observer reliability and correlation between the change in MLMES and in subjective measures were also investigated.

Results: Thirty patients were assessed. The MLMES significantly correlated with visual analogue scale, SNOT-22, global anchor and nasal symptom score. The change in MLMES correlated with the change in SNOT-22 and nasal symptom score. The inter-observer and intra-observer reliability were excellent.

Conclusion: Objectives measurements for post-ESS patients can be reconsidered to represent the cumulative inflammatory burden of all sinuses. The proposed MLMES represents total sinus inflammatory burden and correlates well with patient reported outcome measures.

Key words: chronic rhinosinusitis, endoscopy, endoscopic sinus surgery, inter-observer reliability, intra-observer reliability

\section{Introduction}

Computed tomography (CT) and endoscopy are both standard objective assessments for evaluating disease severity and therapeutic outcomes of chronic rhinosinusitis (CRS). The assessments are for clinical and research purposes. Although CT is the acknowledged gold standard to demonstrate mucosal thickening and thus oedema, endoscopy has become a routine examination in clinics due to its excellent visualization, low costbenefit, simplicity and avoidance of radiation exposure ${ }^{(1)}$. The addition of endoscopy to CT improves diagnostic accuracy ${ }^{(1)}$. Several endoscopy scoring systems have been proposed. Quantification of CRS disease parameters is important for staging and 
prognosis of disease, monitoring treatment effects, providing evidence for health care providers, directing ongoing treatment to define patients in need of more proactive therapy and as a research outcome tool. Some scoring systems focus of grading polyp and others focus on staging the sinus cavity. However, few reflect the patient experience despite the generally accepted concept that a worse appearance on endoscopy usually equates to a more symptomatic patient.

Many sinus cavity staging systems incorporate endoscopic findings with radiological findings ${ }^{(2,3)}$, prior surgery, polyp severity, infection and patient immune status ${ }^{(3)}$ or based solely on the extent of inflammatory disease ${ }^{(4)}$. The Lund Mackay postoperative endoscopic score (LMES) ${ }^{(5,6)}$ is a sinus cavity staging system that scores endoscopic appearance of the sinus cavities by incorporating polyp, oedema, discharge, crusting and scarring. Although the LMES has never been validated, its simplicity makes it widely used and accepted.

While it has been demonstrated that endoscopy scores do not correlate with patient symptoms ${ }^{(7-9)}$, this is not the case in clinical practice. The correct statement regarding the relationship of endoscopy to the patient experience should be; 'To date, endoscopy assessed by current or existing endoscopy scoring systems does not correlate with symptoms'. More recently, PeriOperative Sinus Endoscopy (POSE) ${ }^{(10)}$ and Discharge, Inflammation and Polyp/oedema (DIP) ${ }^{(11)}$ scoring systems have been developed. However, these endoscopy scoring systems fail to correlate with patient symptoms ${ }^{(10,11)}$.

Although specifically designed for allergic fungal rhinosinusitis, the staging system proposed by Philpott and colleagues ${ }^{(12)}$ proposes the concept of cumulative score of all sinus cavities. This method of sinus scoring is well suited for post-operative sinus cavities of patients with CRS. By scoring every single cavity with a ten-grade system of mucosal inflammation, the total score represents the cumulative inflammatory burden of all sinus cavities. Traditional LMES divides the sinuses into two common cavities. Each common cavity is scored as a single unit. However, LMES does not reflect the burden of the whole paranasal sinus system. We present the Modified Lund Mackay Postoperative Endoscopy Score (MLMES), a novel endoscopy scoring system for post endoscopic sinus surgery (ESS) patients that aims to better describe the burden of inflammatory changes in CRS incorporating evidence of active inflammation and potential infective exacerbation.

\section{Materials and methods}

Patient population

Adult patients ( $>18$ years) with CRS with or without polyps who underwent ESS in a tertiary referral clinic were prospectively recruited. CRS patients were defined according to EP3OS ${ }^{(13)}$. All patients underwent ESS after failing previous medical therapy.

\section{Study design}

A prospective study was conducted. The study had ethical approval from the St Vincent's Hospital institutional review board. All patients provided informed consent before enrolment. Follow-up occurred at 6 weeks and 3 months after ESS. At each follow-up visit, subjective measurements including visual analoguescale (VAS) of total severity of rhinosinusitis symptoms, Sino-Nasal Outcome Test 22 (SNOT-22), global anchor score of nasal function and a nasal symptom score (0-5, 5 symptoms: nasal obstruction, thick nasal discharge, post nasal discharge, smell dysfunction and facial pain) was collected. Global anchor score was assessed on a 13 pointLikert scale. Patients were asked to rate their change in global nasal function from -6 (significant deterioration) to +6 (significant improvement), with 0 representing no change. Nasal endoscopy was performed and recorded. Endoscopic appearance from the video was scored using traditional LMES and the proposed MLMES endoscopy scoring systems. Fifty percent of the patient videos were independently assessed by a second investigator. All videos were re-scored blindly by the first assessor three months later. The scoring sheet is displayed in Figure 1. Assessors were blinded to patient name, subjective score and follow-up visit time point. The correlation between endoscopy score and subjective measures and the correlation between the change in MLMES and the change in subjective measures: VAS, SNOT-22, global anchor score and nasal symptom score were analyzed. Inter- and intra-rater reliability was also analyzed.

\section{Modified Lund Mackay Postoperative Endoscopy Score (MLMES)}

The endoscopic appearances of all ten post ESS cavities (left and right maxillary, ethmoid, sphenoid, frontal sinuses and olfactory fossa) are quantified for mucosal inflammation (0-6; $0=$ normal mucosa, $1=$ mild edematous mucosa with patent cavity, 2 = severe oedematous mucosa with compromised cavity, $3=$ mild polypoid mucosa with patent cavity, $4=$ severe polypoid mucosa with compromised cavity, $5=$ polyp confined within cavity, 6 = polyp extending beyond cavity), mucus ( $0-2 ; 0=$ none, $1=$ clear and thin, $2=$ thick and eosinophilic) and purulent discharge (0, 2;0 = absent, 2 = present). This produces a score of $0-100$. The MLMES only applies to post-operative sinus cavities. Lothrops cavities are scored as two frontal sinuses separately. Non-pneumatized sinuses and unoperated non-diseased sinuses are scored as zero as they do not contribute to the inflammatory burden. Olfactory fossa is assessed by assessing the cleft between nasal septum and middle turbinate anteriorly and superior turbinate posteriorly. Details are illustrated in Figure 2. 


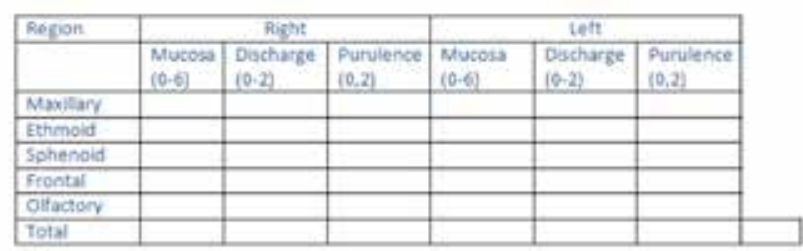

Figure 1. Scoring sheet for Modified Lund Mackay Postoperative Endoscopy Score.
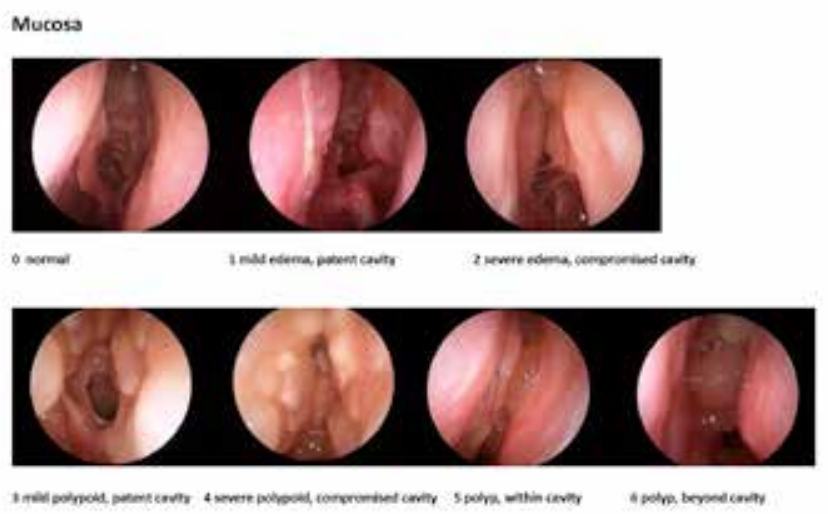

Mucus
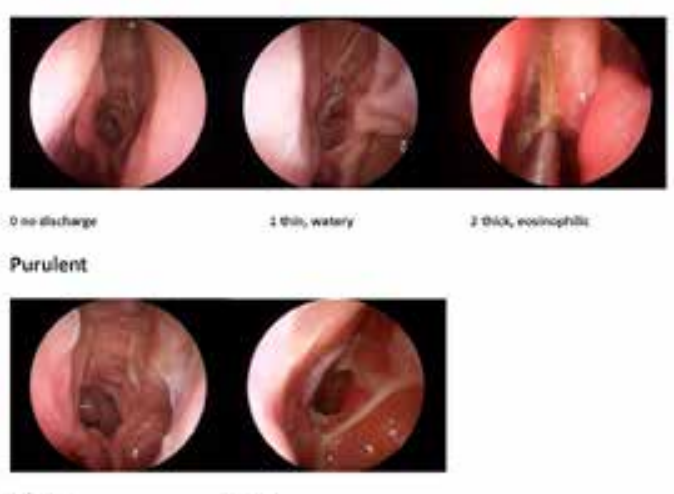

2 prement

Figure 2. The endoscopic appearances of mucosal inflammation (0-6; 0 $=$ normal mucosa, 1 = mild edematous mucosa with patent cavity, 2 = severe edematous mucosa with compromised cavity, $3=$ mild polypoid mucosa with patent cavity, 4 = severe polypoid mucosa with compromised cavity, $5=$ polyp confined within cavity, $6=$ polyp extending beyond cavity), mucus $(0-2 ; 0=$ none, $1=$ clear and thin, $2=$ thick and eosinophilic) and purulent discharge (0, 2;0 = absent, 2 = present).

\section{Statistical analysis}

Descriptive parametric data was presented as percentage, mean and standard deviation (SD). Pearson correlation coefficients were performed for linear relationship of two sets of scale variables. Intraclass correlation coefficient (single measures, two-way mixed effects model) was used to assess the inter-observer and intra-observer reliability. Statistical analyses were performed using SPSS v 20.0 (Statistical Package for the Social Sciences, Chicago, IL, USA).

\section{Results}

\section{Patient population}

Thirty patients were assessed. The mean age was $48.2 \pm 13.0$ years. Fourteen (46.7\%) were female. Nine (30.0\%), twenty (66.7\%) and one (3.3\%) were CRS without polyps, CRS with polyps and allergic fungal sinusitis, respectively. All patients (100\%) had diffuse inflammation in all sinuses and received bilateral wide endoscopic sinus surgery of all sinuses. Patient reported outcomes and endoscopy score are shown in Table1.

The correlation between endoscopy score and subjective measures

The MLMES significantly correlated with visual analogue scale $(r=0.50, p=0.05)$, SNOT-22 $(r=0.46, p=0.01)$, global anchor $(r=0.38, p=0.04)$ and nasal symptom score $(r=0.59, p<0.01)$. LMES significantly correlated with visual analogue scale $(r=$ $0.36, p=0.05)$ and nasal symptom score $(r=0.47, p=0.01)$, but not with SNOT-22 $(r=0.28, p=0.13)$ and global anchor $(r=0.30$, $p=0.12$ ).

The correlation between the change in MLMES and the change in subjective measures

The change in MLMES significantly correlated with the change in SNOT-22 $(r=0.47, p=0.01)$ and nasal symptom score $(r=0.55$, $p<0.01)$ but not visual analogue scale $(r=0.04, p=0.83)$ and global anchor $(r=0.11, p=0.60)$. The LMES could not provide sensitivity to change over time in SNOT-22 $(r=0.26, p=0.19)$, nasal symptom score $(r=0.36, p=0.06)$, visual analogue scale $(r=0.09, p=0.66)$ and global anchor $(r=0.001, p=1.00)$. The MLMES reduced in keeping with improvements in symptoms and the global nasal function score that were not reflected in the LMES (Table 1).

Table 1. Patient report outcomes and endoscopy score (mean \pm SD) of patient population at 6 week and 3 month post-operative visits.

\begin{tabular}{lcc|}
\hline Group & $\mathbf{6}$ weeks visit & $\mathbf{3}$ months visit \\
\hline Total VAS & $1.9 \pm 1.3$ & $1.6 \pm 1.1$ \\
\hline SNOT-22 & $0.9 \pm 0.8$ & $0.8 \pm 0.6$ \\
\hline Global anchor & $3.1 \pm 2.2$ & $3.7 \pm 1.6$ \\
\hline Nasal symptom score & $1.2 \pm 0.9$ & $0.9 \pm 0.7$ \\
\hline LMES & $4.8 \pm 2.3$ & $5.0 \pm 2.8$ \\
\hline MLMES & $12.3 \pm 9.3$ & $10.4 \pm 12.0$
\end{tabular}




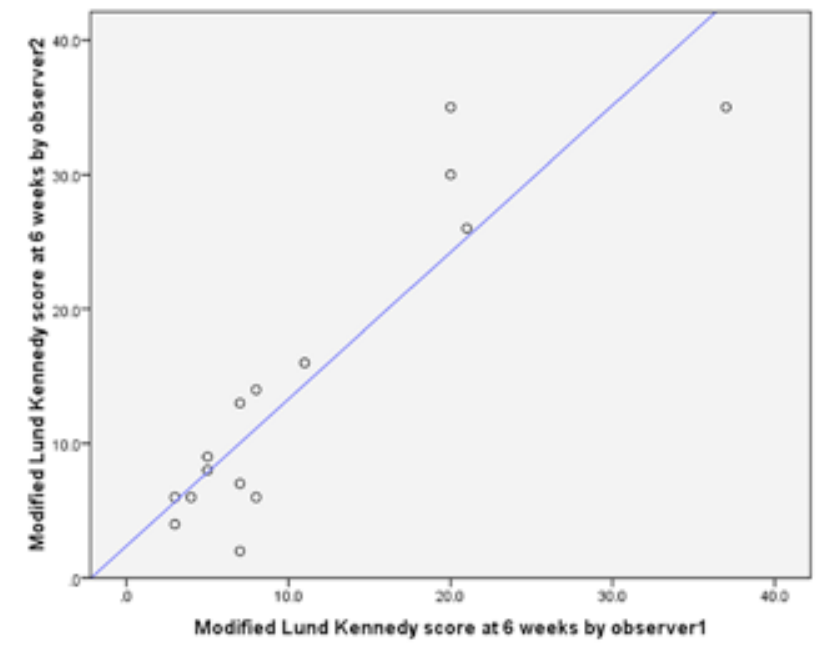

Figure 3. Inter-rater reliability: scatter dots represent more than 1 data set.

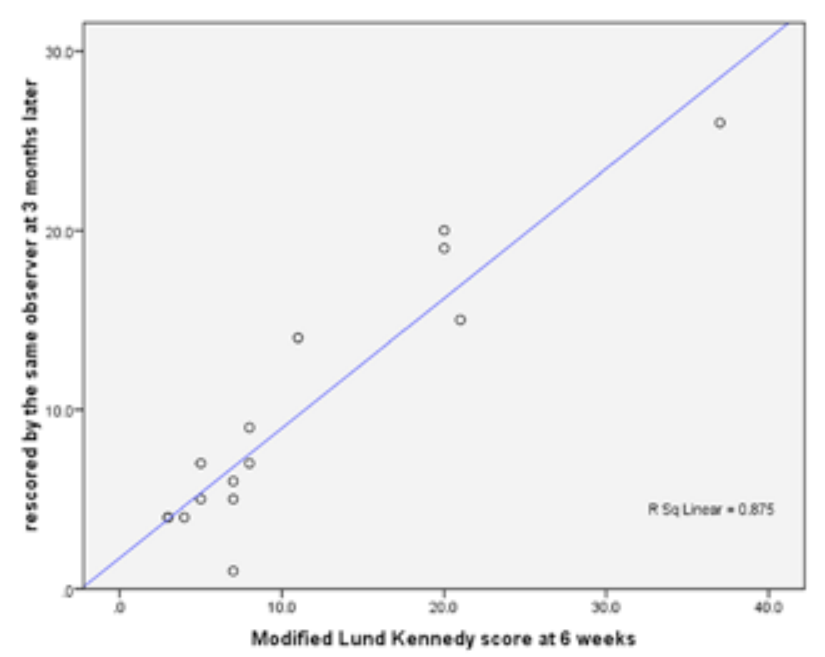

Figure 4. Intra-rater reliability: scatter dots represent more than 1 data set.
Inter-rater reliability and intra-rater reliability

The intraclass correlation coefficient showed a significant correlation for both inter-rater reliability $(\mathrm{ICC}=0.94, \mathrm{p}<0.01)$ and intra-rater reliability $(\mathrm{ICC}=0.95, \mathrm{p}<0.01)$. Scatter plots for inter and intra-rater reliability are shown in Figure 3 and 4, respectively.

\section{Discussion}

The Modified Lund-Mackay Endoscopy Score is an objective postoperative endoscopy score that reflects the overall inflammatory burden of disease in CRS patients. Quantification of CRS disease parameters is important for staging and prognosis of disease, monitoring treatment effects, providing evidence for health care providers, directing ongoing treatment to define patients in need of more proactive therapy and validated research outcome tool. Although several endoscopy scoring systems exist, they do not adequately reflect the disease burden across all sinus cavities, thus new endoscopy scoring systems are still being sought. The ideal endoscopy scoring system should be easy to use and reproducible. Parameters must accurately reflect inflammatory disease and measure changes in patient symptoms. There is no attempt here to find a score that can reflect both the preoperative state with the much remodeled postoperative sinus cavity. It is the belief of the authors that such comparisons should not be made as they compare two completely different assessments. The focus was to provide a validated tool for better defining the patient and disease process with ongoing therapy after ESS.

Among the existing endoscopy scoring systems, various parameters are incorporated. These parameters should reflect active inflammation to quantify the inflammatory burden. According to EPOS 2012, endoscopic signs, which indicate active inflam- mation are nasal polyp, mucopurulent discharge, mucosal edema and mucosal obstruction ${ }^{(13)}$. Mucosal oedema, polypoid mucosa and nasal polyp are various stages of mucosal inflammation. This concept has been introduced in staging allergic fungal sinusitis by Kupferberg et al. (14), and Philpott et al. ${ }^{(12)}$. MLMES uses this mucosal staging system to score mucosal inflammation. Obstruction of the olfactory cleft and the sinus cavity determines the severity of mucosal inflammation as 'mild' for patent cavity and 'severe' for compromised cavity. Although nasal discharge can be either mucoid or purulent, they might represent different etiologies. While thick mucin may indicate eosinophilic inflammation, purulent discharge often occurs with concurrent bacterial infection. Patients with CRS may have concurrent thick mucus and purulent discharge or may have either of them independently. Thus these two categories of nasal discharge potentially reflect two different kinds of active inflammation and are scored separately. Crust, scar and lateralized middle turbinate, although having potential to cause active inflammation, are not variables of actual inflammation and are not included in the MLMES.

When the sinus cavity is divided into two common cavities, the inflammatory burden is based on the worst affected sinus. According to the MLMES, the inflammatory burden of CRS is an accumulation of the active inflammation of all sinus cavities. Although active inflammation is properly quantified, endoscopy score may not reflect the actual inflammatory burden if all sinus cavities are scored as one single unit. Patients having active inflammation in one single cavity may have less inflammatory burden than those with multiple cavities affected. The concept of cumulative inflammatory burden was introduced by PhilpottJaver ${ }^{(12)}$ and is well suited to scoring post ESS patients. The status of the entire post ESS cavities is better determined by a total 
Table2. Summary of existing endoscopic scoring systems.

\begin{tabular}{|c|c|c|c|c|c|c|c|c|}
\hline & \multicolumn{8}{|c|}{ Scoring system } \\
\hline & \multicolumn{2}{|c|}{ Modified Lund Mackay } & \multicolumn{2}{|r|}{ Lund Mackay } & \multicolumn{2}{|r|}{ POSE } & \multicolumn{2}{|r|}{ DIP } \\
\hline & score & description & score & description & score & description & score & description \\
\hline & $0-6$ & $\begin{array}{l}0=\text { normal mucosa } \\
1=\text { mild oedema, } \\
2=\text { severe oedema, } \\
3=\text { mild polypoid } \\
4=\text { severe polypoid, } \\
5=\text { polyp within } \\
\text { cavity } \\
6=\text { polyp beyond } \\
\text { cavity }\end{array}$ & $0-2$ & $\begin{array}{l}\text { polyp: } \\
0=\text { absence of } \\
\text { polyps, } \\
1=\text { polyps in middle } \\
\text { meatus only, } \\
2=\text { polyps beyond } \\
\text { middle meatus }\end{array}$ & $0-6$ & $\begin{array}{l}\text { ethmoid cavity: } \\
0=\text { normal mucosa, } \\
1=\text { mild oedema, } \\
2=\text { severe oedema, } \\
3=\text { mild polypoid, } \\
4=\text { severe polypoid, } \\
5=\text { polyp beyond } \\
\text { middle meatus but } \\
\text { not to the inferior } \\
\text { turbinate, } \\
6=\text { polyp beyond } \\
\text { the upper border of } \\
\text { the inferior turbinate }\end{array}$ & $0-10$ & $\begin{array}{l}\text { polyp } / \text { oedema: } \\
0=\text { normal mucosa, } \\
5=\text { marked oedema/ } \\
\text { no polyps, } \\
10=\text { polyps filling } \\
\text { nasal cavity }\end{array}$ \\
\hline \multirow[t]{3}{*}{$\begin{array}{l}\text { mucosal } \\
\text { inflammation }\end{array}$} & & & $0-2$ & $\begin{array}{l}\text { oedema: } \\
0=\text { absent } \\
1=\text { mild } \\
2=\text { severe }\end{array}$ & $0-2$ & $\begin{array}{l}\text { frontal recess } \\
\text { sinus: } \\
0=\text { patent, } \\
1=\text { narrowed, } \\
\text { edema, } \\
2=\text { obstructed, } \\
\text { infected, severely } \\
\text { inflamed }\end{array}$ & $0-2$ & $\begin{array}{l}\text { inflammation: } \\
0=\text { absent } \\
1=\text { mild } \\
2=\text { severe }\end{array}$ \\
\hline & & & & & $0-2$ & $\begin{array}{l}\text { sphenoid sinus: } \\
0=\text { patent, } \\
1=\text { narrowed, } \\
\text { oedema, } \\
2=\text { obstructed, } \\
\text { infected, severely } \\
\text { inflamed }\end{array}$ & & \\
\hline & $0-2$ & $\begin{array}{l}0=\text { no discharge, } \\
\text { I= clear, thin } \\
\text { discharge, } \\
2=\text { thick, purulent } \\
\text { discharge }\end{array}$ & $0-2$ & $\begin{array}{l}0=\text { no discharge, } \\
\text { I= clear, thin } \\
\text { discharge, } \\
2=\text { thick, purulent } \\
\text { discharge }\end{array}$ & $0-2$ & $\begin{array}{l}0=\text { no discharge, } \\
\text { I= clear, thin } \\
\text { discharge, } \\
2=\text { thick, purulent } \\
\text { discharge }\end{array}$ & $0-10$ & $\begin{array}{l}0=\text { no discharge } \\
5=\text { thick discharge } \\
10=\text { purulent } \\
\text { discharge }\end{array}$ \\
\hline purulent & $0-2$ & $\begin{array}{l}0=\text { absent } \\
2=\text { present }\end{array}$ & & & & & & \\
\hline scarring & & not assessed & $0-2$ & $\begin{array}{l}0=\text { absent } \\
1=\text { mild } \\
2=\text { severe }\end{array}$ & & not assessed & & not assessed \\
\hline crusting & & not assessed & $0-2$ & $\begin{array}{l}0=\text { absent } \\
1=\text { mild } \\
2=\text { severe }\end{array}$ & $0-2$ & $\begin{array}{l}0=\text { absent } \\
1=\text { mild } \\
2=\text { severe }\end{array}$ & & not assessed \\
\hline \multirow[t]{2}{*}{ middle turbinate } & & not assessed & & not assessed & $0-1$ & $\begin{array}{l}0=\text { normal } \\
1=\text { synechia } \\
\text { lateralized }\end{array}$ & & not assessed \\
\hline & & & & & $0-2$ & $\begin{array}{l}\text { stenosis: } \\
0=\text { normal, } \\
1=\text { narrowed, } \\
2=\text { complete } \\
\quad \text { obstruction }\end{array}$ & & \\
\hline middle meatus & & not assessed & & not assessed & $0-2$ & $\begin{array}{l}\text { maxillary sinus } \\
\text { content: } \\
0=\text { normal, } \\
1=\text { oedema or thin } \\
\text { discharge, } \\
2=\text { purulence or } \\
\text { allergic mucin }\end{array}$ & & not assessed \\
\hline
\end{tabular}


Table 2 (continued). Summary of existing endoscopic scoring systems.

\begin{tabular}{|c|c|c|c|c|c|c|c|c|}
\hline cavities & & $\begin{array}{l}10 \text { cavities: } \\
\text { left and right sides of } \\
\text { maxillary, ethmoid, } \\
\text { sphenoid, frontal } \\
\text { and olfactory fossa }\end{array}$ & & $\begin{array}{l}2 \text { cavities: } \\
\text { left and right sides } \\
\text { of nose }\end{array}$ & & $\begin{array}{l}8 \text { cavities: } \\
\text { left and right sides of } \\
\text { ethmoid, sphenoid, } \\
\text { frontal and middle } \\
\text { meatus }\end{array}$ & & $\begin{array}{l}2 \text { cavities: } \\
\text { left and right sides } \\
\text { of nose }\end{array}$ \\
\hline validation & & $\begin{array}{l}\text { 1. correlation with } \\
\text { patient report out- } \\
\text { comes } \\
\text { 2. correlation with } \\
\text { LMES } \\
3 \text { sensitivity to } \\
\text { change } \\
4 \text {. intra and inter } \\
\text { rater reliability }\end{array}$ & & $\begin{array}{l}\text { 1. non-correlation } \\
\text { with patient report } \\
\text { outcomes }^{(10)}\end{array}$ & & $\begin{array}{l}\text { 1. non-correlation } \\
\text { with patient report } \\
\text { outcomes }^{(10)} \\
\text { 2. correlation with } \\
\text { LMES } \\
\text { 3. sensitivity to } \\
\text { change (Significance } \\
\text { was not reported.) }\end{array}$ & & $\begin{array}{l}\text { 1. non-correlation } \\
\text { with patient report } \\
\text { outcomes }{ }^{(11)} \\
\text { 2. correlation with } \\
\text { LMES and POSE } \\
\text { 3. intra and inter } \\
\text { rater reliability }\end{array}$ \\
\hline total score & $0-100$ & & $0-20$ & & $\begin{array}{l}0-32 \\
0-36 \\
0-40\end{array}$ & $\begin{array}{l}\text { Total score may be } \\
32,36 \text { or } 40 \text { up to } \\
\text { the extent of sinus } \\
\text { surgery. Score can be } \\
\text { adjusted being out } \\
\text { of } 40 \text { for analysis. }\end{array}$ & $0-60$ & \\
\hline
\end{tabular}

score rather than dominated by the worst affected cavity.

The olfactory fossa is often overlooked by clinicians and researchers. Active mucosal inflammation in this area directly affects smell, symptom severity and quality of life ${ }^{(15)}$. It is observed by the authors that some patients with healthy sinus cavities may complain of severe olfactory dysfunction when the olfactory fossa is affected. Thus, the olfactory fossa is acknowledged by MLMES as an important unit contributing to a total endoscopy score. Examples of various mucosal inflammation of olfactory fossa and how they are scored are displayed in Figure 5.

MLMES is a practical tool with excellent intra-rater and inter-
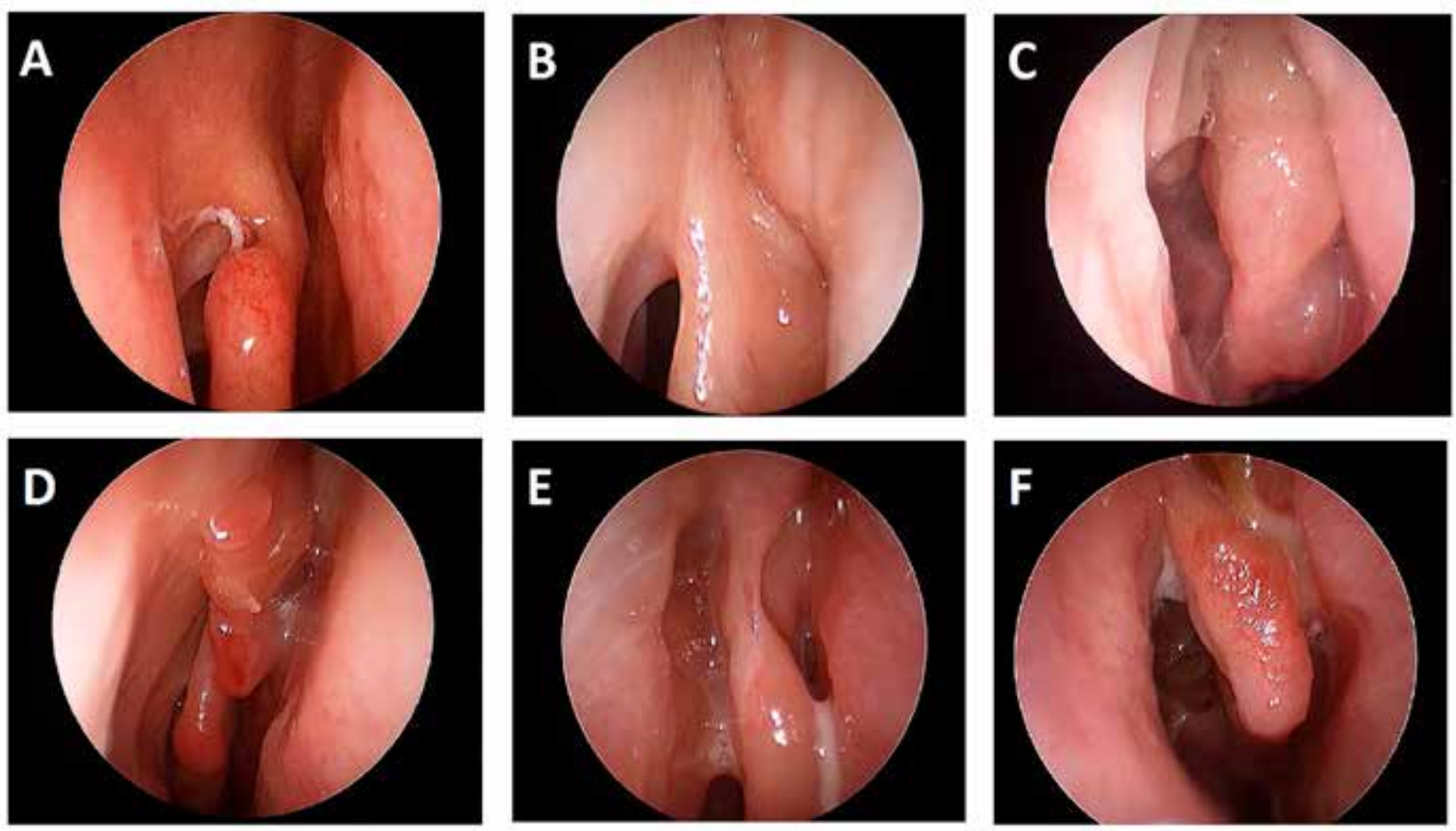

Figure 5. The endoscopic appearances of various mucosal inflammation of right olfactory fossa: A) normal mucosa (mucosal score 0), B) severe edema (mucosa score 2), C) severe polypoid (mucosa score 4), D) polyp beyond cavity (mucosa score 6), E) thin discharge (mucus score 1), F) thick discharge (discharge score 2). 
rater reliability. The maximum score of 100 makes it easy to remember. The MLMES correlates with subjective patient measures as well as changes in patient symptoms with time.

The review of the existing endoscopic scoring systems is displayed in Table 2. LMES is acknowledged for its simplicity and ease to remember. LMES and DIP score one side of the nasal cavity as one unit which may skew their endoscopy score. POSE accumulates scores from eight cavities to reflect the whole picture; however parameters which may not indicate active inflammation, such as crusting and middle turbinate lateralization are also scored by POSE. Its maximum score, which can be either 32,36 or 40 depending on the extent of sinus surgery, make the system complex. Neither LMES, POSE nor does DIP significantly correlate with patient reported outcomes.

Ultimately, no single tool will reflect the patient experience nor will a simple patient reported outcome be a defining factor to predict prognosis and stage the disease process. EPOS 2012 proposed a staging system, with intent to validate a future system with data, which focused on patient reported symptoms, endoscopy and systemic medication use ${ }^{(13)}$. Our own assessment, suggests that all 3 factors provide the best prediction of long term control and it is likely that nasal congestion/obstruction combined with inflammation on endoscopy with the need for systemic medication (the NOSE system: Nasal Obstrcution, Systemic medication, Endoscopy) may be the best predictor of disease progression (unpublished data).

\section{Conclusions}

The proposed MLMES represents the cumulative inflammatory burden of all sinuses post ESS. The MLMES correlates with patient report outcome measures as well as changes in the patient symptoms over time. It provides a robust and reproducible scoring system with excellent inter and intra-rater reliability.

\section{Authorship contribution}

KS: data collection, data analysis and manuscript preparation; DD: data collection, manuscript review;

LK: data collection, manuscript review;

RS: data collection, manuscript review;

EP: data collection, manuscript review;

$\mathrm{RJH}$ : study concept, data analysis, manuscript review

\section{Conflict of interest}

Larry Kalish is on the speaker bureau for Merck Sharp Dolme (MSD), Takeda and Care Pharmaceuticals.

Raymond Sacks is consultant for Medtronic and Nycomed, speakers' bureau for Merck Sharp Dolme and Arthrocare.

Richard J. Harvey has served on an advisory board for Schering Plough and Glaxo-Smith-Kline, previous consultant with Medtronic, Olympus and Stallergenes, speakers' bureau for Merck Sharp Dolme and Arthrocare and has received grant support from NeliMed.

Kornkiat Snidvongs, Dustin Dalgorf, Elenor Pratt have no financial disclosures and no conflict of interest.

\section{References}

1. Bhattacharyya N, Lee LN. Evaluating the diagnosis of chronic rhinosinusitis based on clinical guidelines and endoscopy. Otolaryngol Head Neck Surg. 2010; 143: 147-151.

2. Jacobs JB, Gittelman P, Holliday R. Endoscopic sinus surgery for ostiomeata disease. Am J Rhinol. 1990; 4: 41-43.

3. Gaskins RE. A surgical staging system for chronic sinusitis. Am J Rhinol. 1992; 6: 5-12.

4. Kennedy DW. Prognostic factors, outcomes and staging in ethmoid sinus surgery. Laryngoscope. 1992; 102 (Suppl 57): 1-18.

5. Lund VJ, Kennedy DW. Staging for rhinosinusitis. Otolaryngol Head Neck Surg. 1997; 117: S35-40.

6. Lund VJ, Mackay IS. Staging in rhinosinusitis Rhinology. 1993; 31: 183-184.

7. Ryan WR, Ramachandra T, Hwang PH Correlations between symptoms, nasal endoscopy, and in-office computed tomog raphy in post-surgical chronic rhinosinusitis patients. Laryngoscope. 2011; 121: 674-648.

8. Kaplan BA, Kountakis SE. Role of nasal endoscopy in patients undergoing endo- scopic sinus surgery. Am J Rhinol. 2004; 18: 161-164.

9. Liu Z, Wang H, Lu X, You XG, Gao Q, Cui Y. Correlation between rhinosinusitis symptoms and objective sinus examinations. Lin Chung Er Bi Yan Hou Tou Jing Wai Ke Za Zhi. 2007; 21: 483-485.

10. Wright ED, Agrawal S. Impact of perioperative systemic steroids on surgical outcomes in patients with chronic rhinosinusitis with polyposis: evaluation with the novel Perioperative Sinus Endoscopy (POSE) scoring system. Laryngoscope. 2007; 117: Suppl 115: 1-28.

11. Durr ML, Pletcher SD, Goldberg AN, Murr A. A novel sinonasal endoscopy scoring system: the discharge, inflammation, and polyps/edema (DIP) score. Int Forum Allergy Rhinol. 2013; 3: 66-72.

12. Philpott CM, Javer AR, Clark A. Allergic fungal rhinosinusitis - a new staging system. Rhinology. 2011; 49: 318-323.

13. Fokkens WJ, Lund VJ, Mullol J, et al. European Position Paper on Rhinosinusitis and Nasal Polyps 2012. Rhinol Suppl. 2012 (23): 1-298.
14. Kupferberg SB, Bent JP, 3rd, Kuhn FA. Prognosis for allergic fungal sinusitis. Otolaryngol Head Neck Surg. 1997; 117: 35-41.

15. Kim DW, Kim JY, Jeon SY. The status of the olfactory cleft may predict postoperative olfactory function in chronic rhinosinusitis with nasal polyposis. Am J Rhinol Allergy. 2011; 25: e90-94.

Kornkiat Snidvongs

The Australian School of Advanced

Medicine

2 Technology Place

Macquarie University NSW 2109

Australia

Tel: +61 (0) 298123500

Fax: +61 (0) 298123600

E-mail: drkornkiat@yahoo.com 